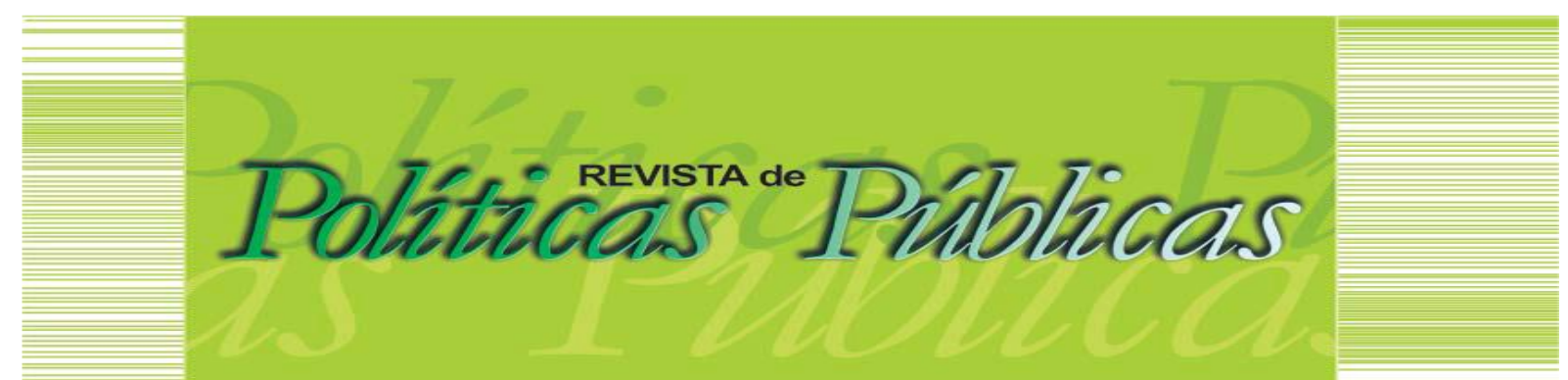

\title{
PROGRAMA NACIONAL DE HABITAÇÃO RURAL E CONDIÇÕES DE MORADIA EM PEQUENAS CIDADES NA AMAZÔNIA PARAENSE
}

\author{
Walkiria Maria Sousa da Silva ${ }^{1}$ \\ Joana Valente Santana ${ }^{2}$ \\ Katia Maria dos Santos $\mathrm{Melo}^{3}$ \\ Pedro Paulo de Miranda Araujo Soares ${ }^{4}$
}

\begin{abstract}
Resumo
O artigo analisa o direito à moradia rural em pequenos municípios paraenses (Abaetetuba, Santa Izabel do Pará e Soure), por meio do Programa Nacional de Habitação Rural (PNHR), considerando aspectos socioeconômicos das famílias. A pesquisa é orientada pelo materialismo histórico e dialético, realizando levantamento bibliográfico, documental e de campo, com formulários e entrevistas semiestruturadas. Os resultados mostram que o PNHR oferece 0 acesso à nova casa; 0 sentimento de segurança; a existência de banheiro interno; os serviços de saúde e de educação. Por outro lado, as famílias relatam problemas de infraestrutura da casa e do entorno, além da dificuldade de pagamento da mensalidade. Conclui que o PNHR desconsidera as particularidades regionais, como a necessidade de compartimentos amplos de cozinha e pátio, com vistas à preservação da sociabilidade do modo de vida rural amazônico.
\end{abstract}

Palavras-chave: Habitação rural no Pará. Direito à moradia. Política habitacional. Programa Nacional de Habitação Rural.

\section{NATIONAL RURAL HOUSING PROGRAM AND HOUSING CONDITIONS IN SMALL CITIES IN THE AMAZON}

\section{Abstract}

The article analyzes the right to housing in rural areas of small cities in Pará, Brazil (Abaetetuba, Santa Izabel do Pará and Soure), considering the socioeconomic characteristics of the beneficiaries of the National Rural Housing Program (PNHR). It draws upon the historical dialectical materialism and relies on bibliographic, documentary, and field surveys, when the authors conducted interviews. Data suggests the access to the new house, the feeling of security, the inside bathroom, the presence health and education services are positive aspects of the PNHR. Moreover, the downsides are the lack of urban infrastructure, poor quality of house construction, and difficulties in affording the monthly fee. It concludes the PNHR disregards regional particularities as the need for large kitchen and patio compartments, in order to preserve the sociability of the Amazonian rural way of life.

Keywords: Rural housing in Pará. Right to housing. Housing policy. National Rural Housing Program.

Artigo recebido em: 21/12/2020 Aprovado em: 20/05/2021

DOI: http://dx.doi.org/10.18764/2178-2865.v25n1p480-499

\footnotetext{
${ }^{1}$ Assistente Social. Mestre em Serviço Social pela Universidade Federal do Pará (UFPA). Doutoranda do Programa de Pós graduação em Serviço Social (PPGSS) da Universidade Federal do Pará. E-mail: kiria_maria@yahoo.com.br

2 Assistente Social. Doutora em Serviço Social pela Universidade Federal do Rio de Janeiro (UFRJ). Docente da Faculdade e do Programa de Pós-Graduação em Serviço Social (PPGSS) da Universidade Federal do Pará (UFPA). Bolsista Produtividade em Pesquisa do CNPq. Coordenadora Adjunta da Área de Serviço Social na Capes (2018-2022).Email: joanavalente@ufpa.br.

${ }^{3}$ Doutora em Política Social pela Universidade de Brasília (UNB). Professora da Universidade do Estado do Pará (UEPA). Pesquisadora do Grupo sobre Tráfico de Pessoas, Violência e Exploração Sexual de Mulheres, Crianças e Adolescentes (VIOLES-UnB). Pesquisadora do Grupo Interdisciplinar de Pesquisa em Sociedade, Saúde e Meio Ambiente na Amazônia (GIPSSMAA-UEPA). Coordenadora do Campus XVII Vigia-UEPA. E-mail: katiasmel1@gmail.com

${ }_{4}^{4}$ Antropólogo. Doutor em Antropologia Social pela Universidade Federal do Rio Grande do Sul (UFRGS). Bolsista PNPD/CAPES no Programa de Pós-Graduação em Serviço Social (PPGSS) da Universidade Federal do Pará (UFPA). Email: pedropaulo.soares@yahoo.com.br
} 


\section{INTRODUÇÃO}

Este artigo apresenta parte dos resultados de uma pesquisa na área do Serviço Social ${ }^{1}$ que teve por objetivo analisar o direito à moradia no meio rural em pequenos municípios paraenses, por meio do Programa Nacional de Habitação Rural (PNHR), demonstrando as respostas apresentadas pelo Programa e considerando a realidade socioeconômica das famílias em áreas onde residem pessoas com baixo nível de renda.

O Serviço Social brasileiro tem avançado nos estudos sobre a questão da moradia como uma das expressões da questão social. Esses estudos têm a tarefa de contribuir com a formação e 0 trabalho profissional, a defesa dos direitos da classe trabalhadora e a organização política da sociedade. No caso da região amazônica, há um desafio particular devido às suas condições históricas no contexto das desigualdades regionais, como assinala Teixeira (2008, p. 141):

Com indicadores hoje alarmantes de devastação da floresta, de poluição dos rios e de expansão da pobreza, que toma a forma massiva e degradante, a região amazônica exige do Serviço Social uma atualização teórica e um compromisso ético-político. E, das políticas públicas, uma fuga à padronização que homogeneíza a realidade brasileira nos moldes das referências sul/sudeste.

O estado do Pará possui 144 municípios e extensão territorial de 1.245.870,798 km². Segundo dados estimativos do Instituto Brasileiro de Geografia e Estatística - IBGE referentes a 2019, tem população estimada em 8.602 .865 pessoas e rendimento mensal domiciliar per capita de $\mathrm{R} \$ 807,00$ - um dos índices mais baixos entre os estados da federação, perdendo apenas para 0 Maranhão, este com renda per capita de R $\$ 636,00$ (INSTITUTO BRASILEIRO DE GEOGRAFIA E ESTATíSTICA, 2020a). Em 2010, a população urbana no Pará girava em torno de $68,5 \%$, enquanto a população rural representava cerca de $31,5 \%$ do total (INSTITUTO BRASILEIRO DE GEOGRAFIA E ESTATÍSTICA, 2020b).

As condições de moradia da classe trabalhadora no Brasil são o resultado de um processo de ocupação socioterritorial que levou populações empobrecidas a habitar espaços sem infraestrutura urbana e insalubres do ponto de vista ambiental. Estes são fatores que levam o país a apresentar graves problemas de inadequação habitacional, com destaque para a carência de infraestrutura urbana, o que é ainda mais acentuado na região Norte. Com base nos dados do IBGE para o ano de 2016, Santana (2018, p. 99) afirma:

Enquanto no País, a carência de infraestrutura corresponde a $26,4 \%$ do total de domicílios particulares permanentes, na Região Norte, esse dado representa $63,1 \%$, sendo o maior percentual quando comparado às demais regiões (Nordeste: $43,4 \%$; Sudeste: $11,7 \%$, Sul: 23,8\% e Centro Oeste: $43,3 \%$ ). 
Em 2010, o estado do Pará possuía um déficit habitacional de 423,4 mil domicílios, correspondendo a $51,9 \%$ do total da região Norte e a $6,3 \%$ do Brasil. Os componentes do déficit habitacional que mais se destacaram foram as habitações precárias e a coabitação familiar. Por sua vez, "o déficit rural no Estado representava em média mais de $1 / 3(38,3 \%)$ do déficit total" (PARÁ, 2014, p. 69, grifo nosso). Em relação à inadequação habitacional, o componente mais expressivo é carência de infraestrutura, correspondendo a 1.524.327 domicílios. A principal inadequação se refere à ausência de pelo menos um dos elementos da "infraestrutura (1.524.327 domicílios): água potável, esgotamento sanitário, coleta de lixo domiciliar e energia elétrica. A segunda maior inadequação verificada era a ausência de unidade sanitária privativa [...] em cerca de 480 mil domicílios" (PARÁ, 2014, p. 80). O Plano Estadual de Habitação de Interesse Social (PEHIS) também demonstrou que havia uma expressiva inadequação na carência de infraestrutura concernente à inexistência de unidade sanitária privativa na área rural do estado (PARÁ, 2014).

No período de 2008 a 2015, o Pará passou a implementar o PNHR, o qual é um subprograma do Programa Minha Casa Minha Vida, atendendo 31 municípios paraenses em áreas rurais. Nesse sentido, a pesquisa que deu base a este artigo definiu a seguinte questão: de que maneira o Programa Nacional de Habitação Rural contribui para a garantia do direito à moradia no âmbito rural em pequenos municípios paraenses?

Com base no método do materialismo histórico e dialético (MARX, 1974), a pesquisa teve como procedimentos metodológicos o levantamento bibliográfico, documental ${ }^{2}$ e de campo $^{3}$, este último realizado em três municípios paraenses (Abaetetuba, Santa Izabel do Pará e Soure)4. Em Abaetetuba, do universo de 48 Unidades Habitacionais (UH), foram aplicados 08 formulários na Comunidade de Santa Terezinha, Ramal do Palhal e Colônia Velha. Em Santa Izabel do Pará, do total de $18 \mathrm{UH}$, foram aplicados 14 formulários no Distrito de Americano, Agrovila de Ferreira Pena. Em Soure, do total de $50 \mathrm{UH}$, foram aplicados 18 formulários de pesquisa. Foram realizadas 08 entrevistas mediante roteiro semiestruturado: com 02 Assistentes Sociais de Abaetetuba, via e-mail; 01 com o exSecretário de Habitação de Soure; e com 05 moradores, sendo estas últimas realizadas in loco - 01 em Abaetetuba, 02 em Santa Izabel do Pará e 02 em Soure. Ao todo, a pesquisa envolveu 48 pessoas. Para efeito deste artigo, será priorizada a apresentação dos dados referentes a: Informações sobre o morador; Trabalho e renda; Situação da moradia; Situação dos serviços públicos; e Percepção do morador. Os dados dos três municípios serão apresentados de forma agrupada.

No Brasil, a maioria dos estudos sobre a questão da habitação enfoca a vida dos moradores em áreas precárias (favelas, baixadas etc.) com alta carência de infraestrutura. Sobre 0 PNHR, um levantamento no Catálogo de Teses e Dissertações da Capes (todos os períodos 
disponíveis na plataforma até o ano 2018) identificou 21 trabalhos de conclusão de curso (18 dissertações de mestrado e 03 teses de doutorado) que estudaram o Programa, incluindo-se a Área de Serviço Social, que produziu apenas 02 trabalhos (SANTOS, 2014; PETERSEN, 2015). 0 levantamento no Portal de Periódicos da Capes segue essa tendência, tendo sido encontrados 13 artigos sobre o tema publicados em periódicos científicos, sendo apenas 01 na Área de Serviço Social (MUNARINI, 2010). Assim os estudos sobre as condições de habitação em áreas consideradas rurais ainda é um desafio para as áreas das humanidades, em especial para o Serviço Social.

Este artigo está dividido em duas seções, além desta introdução e das considerações finais. A primeira apresenta uma discussão sobre as particularidades da questão da habitação na Amazônia e o PNHR. A segunda apresenta os resultados da pesquisa.

\section{PARTICULARIDADES DA QUESTÃO DA HABITAÇÃO NA AMAZÔNIA E O PROGRAMA NACIONAL DE HABITAÇÃO RURAL}

No clássico texto "A Justiça Social e a Cidade", Harvey (1980, p. 86) discute sobre as necessidades humanas que deveriam ser atendidas de forma comum a todos os indivíduos: alimento, habitação, cuidados médicos, educação, serviço social e ambiental, bens de consumo, oportunidades de lazer, amenidades de vizinhança e facilidades de transporte. No século XIX, Engels (2015) já discutia a habitação como uma das necessidades humanas de difícil acesso pela classe trabalhadora do período, considerando a escassez da moradia como resultante, entre outras determinações, da desigualdade de classe na ordem burguesa.

$\mathrm{Na}$ história do Brasil, a produção habitacional expressa a profunda desigualdade econômica e social advinda da estrutura de classe, da herança patrimonialista, da concentração de poder e da recorrência de privilégios políticos por aqueles que detêm o controle econômico. É o que discute o trecho a seguir:

\footnotetext{
A busca dos trabalhadores pela moradia, uma das primeiras necessidade humanas, revertese de uma disputa desigual, em primeiro lugar pela questão da propriedade fundiária (que está na raiz da questão urbana) e, em segundo lugar, pela ação do Estado, que historicamente, no Brasil, atende aos interesses das frações de classe dominante, apenas incluindo alguns direitos dos trabalhadores quando estes alcançam um nivel de movimentação política capaz de forçar o Estado a realizar concessões através de políticas sociais (PERDIGÃO; SANTANA, 2018, p. 217-218).
}

$\mathrm{Na}$ Amazônia, há uma peculiaridade no processo de formação resultante em desigualdades socioespaciais geradas pela intervenção estatal e pela inserção de atividades capitalistas no território, conflitando com usos tradicionais da terra pelas comunidades locais 


\section{PROGRAMA NACIONAL DE HABITAÇÃO RURAL E CONDIÇÕES DE MORADIA EM PEQUENAS CIDADES NA AMAZÔNIA PARAENSE}

(HOLANDA, 2011). Essa dinâmica na região se reflete em municípios com alto índice de pobreza e marcados pela exploração dos recursos naturais e da força de trabalho, revelando a lógica do modo de produção capitalista expressa nas desigualdades sociais vistas nas pequenas cidades amazônicas.

Segundo Cardoso e Lima (2006, p. 82), o processo de ocupação da Amazônia intensificou a formação de cidades, principalmente pela ação do Estado, já que, na região, foi estabelecida uma imposição de ordem territorial definida pela implementação dos grandes projetos. Dessa forma, o território passou a ser organizado para atender aos interesses nacionais "para a geração de energia, exploração mineral e madeireira". Tais processos de ocupação nas cidades produziram a valorização da terra, remetendo o território amazônico à ação de especuladores e relações sociais em que o valor de troca é preponderante em relação ao valor de uso. Isso viabilizou a ação de novos agentes sobre a terra ocupada pelos nativos (mas legalmente devolutas), fazendo com que aqueles se tornassem proprietários fundiários na região, enquanto que os antigos moradores foram expulsos para outras cidades, em busca de oportunidades de trabalho e sobrevivência.

Corroborando com essa análise, Castro (2009) sinaliza que as políticas que favorecem o mercado contrariam os interesses das populações que vivem na Amazônia, uma vez que a noção de território adotada pelas políticas governamentais é diferente da noção de território e territorialidade dos grupos que vivem nessa região. Para Castro (2006, p. 10), os espaços urbano-rural amazônicos "são diversos, múltiplos, dispersos e inseparáveis das diferenciações de classe, de etnias ou de lugares sociais, visualizando as diversas formas de apropriação do território e de disputas pelo lugar na cidade". A dinâmica desses espaços é regida por outra ordem social de tempo e espaço, como aparece no trecho abaixo:

\footnotetext{
A cidade (pequena ou grande) é o lugar onde as pessoas vivem bem ou mal, ricas ou miseráveis [...] é no cotidiano que se tem prazer ou se sofre, se vive e se buscam mecanismos que possibilitem a reprodução de uma nova vida não só econômica, mas social e cultural [...] é nas pequenas cidades do interior, como as da Amazônia, que se coloca de forma mais clara a tendência de imposição do cotidiano como parte de um processo de homogeneização baseado na predominância do valor de troca pelo valor de uso (OLIVEIRA, 1999, p. 203).
}

Sobre o morar no meio rural, o trecho de uma das entrevistas feitas para esta pesquisa reforça o que a literatura acadêmica vem discutindo sobre os modos de vida amazônicos:

\footnotetext{
Área é boa, a convivência com a família, temos campo de futebol e igarapé [...], mas descrevo como um local de muitas dificuldades para viver, não tem trabalho, realizo pequenos trabalhos na roça e limpeza de terrenos para o sustento da família, não temos outros lugares para trabalhar (Morador C, Pesquisa de Campo, Abaetetuba, 2019).
}

De maneira geral os moradores descreveram a área rural em que moram de forma positiva, sendo considerado um espaço adequado para viver, ainda que apresente poucas opções de 
lazer e demais formas de interação comunitária, bem como oportunidades de empregos para a população.

Em detrimento do bem-viver de suas populações, as políticas governamentais implementadas na Amazônia atenderam aos interesses do capital, tanto nacional quanto estrangeiro, os quais objetivavam a exploração desmedida dos recursos presentes na região, especialmente, apropriação de terras, visto que a Amazônia se inseriu efetivamente no mercado mundial e nas estratégias econômicas imperialistas por meio de grandes projetos governamentais e privados, os quais visavam não somente o lucro, mas, o controle da produção de matérias-primas vendidas a baixo custo para as multinacionais, ou seja, favorecendo a acumulação de capital (MARQUES, 2012, p. 37).

As cidades tiveram papel importante nesse processo, ora como suporte às novas atividades econômicas, ora como lócus de reinvestimento de capital. No Pará, as políticas de ocupação e urbanização implementadas pelo Governo Federal impulsionaram o processo de urbanização, gerando e reforçando o agravamento dos problemas habitacionais (HOLANDA, 2011, p. 74). 0 estado apresenta alto índice de carência habitacional, sendo a Região Metropolitana de Belém aquela com maior número de assentamentos precários. Apesar do significante problema habitacional, verifica-se que são as pequenas cidades paraenses que possuem maior parte do déficit e inadequação habitacional (HOLANDA; SANTANA, 2012).

O estado do Pará possuía, em 2010, um déficit habitacional na área rural de, aproximadamente, $38 \%$ do déficit total. A Tabela 1 mostra a situação do déficit rural nos três municípios estudados.

Tabela 1 - Déficit habitacional por situação de domicílios nos municípios estudados - 2010

\begin{tabular}{lcccc}
\hline \multirow{2}{*}{ Municípios estudados } & \multicolumn{4}{c}{ Déficit Habitacional } \\
Abaetetuba & Total & Urbano & Rural & Rural (\%) \\
\cline { 2 - 5 } Santa Izabel do Pará & 6.361 & 3.446 & 2.915 & 45,82 \\
Soure & 3.356 & 2.242 & 1.114 & 33,20 \\
\hline Fon & 1.442 & 1.290 & 152 & 10,57 \\
\hline
\end{tabular}

Fonte: elaborado pelos/as autores/as com dados do IBGE - Censo 2010 a partir do cálculo realizado pela COHAB - Plano Estadual de Habitação de Interesse Social, 2014.

No período de 2008 a 2015, o PNHR, que faz parte do programa Minha Casa Minha Vida, foi implementado no estado do Pará5. O Programa tem como um dos principais objetivos construir Unidades Habitacionais em condições de habitabilidade, salubridade e segurança, o que inclui infraestrutura básica ou, no mínimo, soluções para energia, abastecimento de água potável e esgotamento sanitário (BRASIL, 2012, p. 2-13). No período em referência, o PNHR foi operacionalizado em 31 municípios do Pará, sendo prevista a construção de 5 mil unidades habitacionais na área rural, com investimento de mais de 170 milhões de reais (LIMA et al., 2017). Nos municípios pesquisados 
(Abaetetuba, Santa Izabel do Pará e Soure), foi prevista a construção de 595 unidades habitacionais (Tabela 2).

Tabela 2 - Linha de ação por Programa, investimentos e situação das obras/empreendimentos por Município (valor absoluto e percentual)

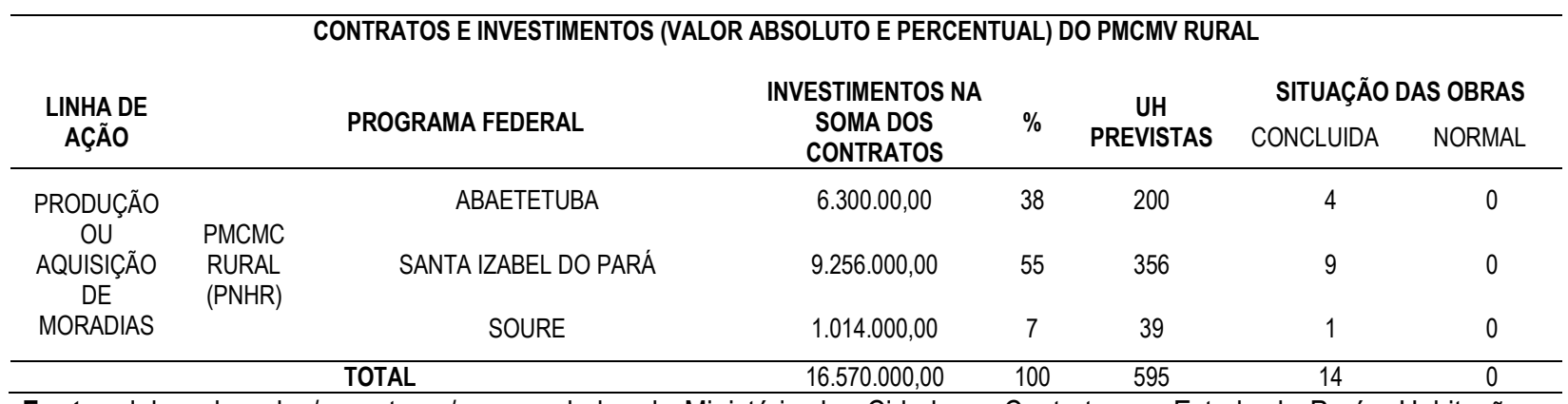

Fonte: elaborado pelos/as autores/as com dados do Ministério das Cidades - Contratos no Estado do Pará - Habitação (janeiro de 2008 a agosto de 2015), 2020.

A seguir, serão apresentados os achados da pesquisa no sentido de apreender os resultados da implementação do PNHR na área rural e discutir a questão do direito à moradia nos municípios estudados.

\section{DIREITO À MORADIA EM MUNICÍPIOS PARAENSES A PARTIR DE ESTUDO SOBRE O PNHR EM ABAETETUBA, SANTA IZABEL DO PARÁ E SOURE}

O estudo realizado nos municípios de Abaetetuba, Santa Izabel do Pará e Soure mostrou que, em relação à identificação, entre 40 dos moradores entrevistados, 87,5\% eram do sexo feminino. Nesse universo também há predominância de raça/cor parda (55\%) e negra/preta (35\%). Trata-se de uma população relativamente jovem, na faixa etária que vai de 18 a 24 anos e de 35 a 44 anos. Também se identificou baixo nível de escolaridade, com 50\% dos entrevistados possuindo o Ensino Fundamental incompleto e 15\% sem escolaridade (Quadro 1).

No aspecto econômico, os indicadores de trabalho e renda demonstram que os moradores são, na maior parte, agricultores, produtores de farinha de tapioca, pescadores e caranguejeiros, os quais possuem rendimentos baixíssimos. Entre eles, 50\% têm renda de menos de 1 salário mínimo; $20 \%$ estão sem renda; e apenas 27,5\% recebem de 1 a 2 salários mínimos. Verificou-se, ainda, que $20 \%$ das famílias entrevistadas dependem exclusivamente do programa de transferência de renda Bolsa Família como meio de subsistência (Quadro 2). 
Quadro 1 - Identificação dos moradores/as

\begin{tabular}{|c|c|c|c|c|c|c|}
\hline Município & $\begin{array}{l}\text { Núm. } \\
\text { Mora- } \\
\text { dores }\end{array}$ & Sexo & Cor (autodeclarada) & Estado civil & Faixa etária & Escolaridade \\
\hline Abaetetuba & 08 & $\begin{array}{l}\text { Mulheres (07) } \\
\text { Homem (01) }\end{array}$ & $\begin{array}{c}\text { Parda (06) } \\
\text { Negra/preta (02) }\end{array}$ & $\begin{array}{c}\text { Solteiros (04) } \\
\text { Casados (02) } \\
\text { Amigados (02) }\end{array}$ & $\begin{array}{l}18-24 \text { anos (3) } \\
25-34 \text { anos (1) } \\
35-44 \text { anos (3) } \\
55-69 \text { anos (1) }\end{array}$ & $\begin{array}{l}\text { Fund. incompleto (4) } \\
\text { Médio completo (2) } \\
\text { Médio incompleto (1) } \\
\text { Sem escolaridade (1) }\end{array}$ \\
\hline $\begin{array}{l}\text { Santa Izabel } \\
\text { do Pará }\end{array}$ & 14 & $\begin{array}{l}\text { Mulheres (11) } \\
\text { Homens (3) }\end{array}$ & $\begin{array}{c}\text { Parda (08) } \\
\text { Branca (04) } \\
\text { Negra/preta (02) }\end{array}$ & $\begin{array}{c}\text { Casados (06) } \\
\text { Solteiros (03) } \\
\text { Divorciados (02) } \\
\text { Viúvos (02) } \\
\text { Amigado (1) }\end{array}$ & $\begin{array}{l}18-24 \text { anos (1) } \\
25-34 \text { anos (2) } \\
35-44 \text { anos (4) } \\
45-54 \text { anos (3) } \\
55-69 \text { anos (2) } \\
70 \text { ou mais (2) }\end{array}$ & $\begin{array}{c}\text { Fund. incompleto (5) } \\
\text { Médio incompleto (3) } \\
\text { Alfabetização (3) Fundamental } \\
\text { completo (1) } \\
\text { Médio incompleto (1) } \\
\text { Sem escolaridade (1) }\end{array}$ \\
\hline Soure & 18 & $\begin{array}{l}\text { Mulheres (17) } \\
\text { Homens (1) }\end{array}$ & $\begin{array}{c}\text { Negra/preta (10) } \\
\text { Parda (08) }\end{array}$ & $\begin{array}{c}\text { Casados (10) } \\
\text { Solteiros (05) } \\
\text { União estável (02) } \\
\text { Amigado (1) }\end{array}$ & $\begin{array}{l}25-34 \text { anos }(7) \\
35-44 \text { anos }(7) \\
45-54 \text { anos }(2) \\
55-69 \text { anos }(2)\end{array}$ & $\begin{array}{l}\text { Fund. incompleto (10) } \\
\text { Médio completo (5) } \\
\text { Médio incompleto (2) } \\
\text { Alfabetização (1) }\end{array}$ \\
\hline
\end{tabular}

Fonte: elaborado pelos/as autores/as com base na pesquisa de campo, 2019.

Quadro 2 - Aspectos econômicos

\begin{tabular}{|c|c|c|c|c|}
\hline Município & Trabalho-Profissão/Ocupação & Mobilidade & Renda & $\begin{array}{l}\text { Recebimento de } \\
\text { Benefícios }{ }^{*}\end{array}$ \\
\hline Abaetetuba & $\begin{array}{c}\text { Agricultores (6) } \\
\text { Dona de Casa (1) } \\
\text { Eletricista (1) } \\
\text { Exerce a sua profissão? (3) }\end{array}$ & $\begin{array}{l}\text { Trabalha na localidade (6) } \\
\text { Se locomovem de barco e ônibus (2) }\end{array}$ & $\begin{array}{c}\text { Sem renda (4) } \\
1 \text { a } 2 \mathrm{SM}^{\star *}(2) \\
\text { Menos de } 1 \mathrm{SM}(1) \\
\text { Sem resposta (1) }\end{array}$ & $\begin{array}{l}\text { Auxílio do } \mathrm{PBF}^{* * *}(7) \\
\mathrm{BPC}^{* * * *}(2) ; \\
\text { Sem resposta. (1) }\end{array}$ \\
\hline $\begin{array}{l}\text { Santa Izabel } \\
\text { do Pará }\end{array}$ & $\begin{array}{c}\text { Agricultores (11), } \\
\text { Aposentados (2), } \\
\text { Desempregado (1). } \\
\text { Exerce a sua profissão? (9) }\end{array}$ & $\begin{array}{c}\text { Trabalha na localidade (10) } \\
\text { Se locomovem de ônibus e bicicleta } \\
(04) \text {, entre } 2 \text { e } 5 \mathrm{~km}\end{array}$ & $\begin{array}{l}01 \text { a } 02 \text { SM (6) } \\
\text { Menos de } 1 \text { SM (6) } \\
\text { Sem renda (2). }\end{array}$ & $\begin{array}{l}\text { Auxílio do PBF (7); } \\
\text { Nenhum benefício (5) } \\
\text { DPVAT }^{* \star \star \star *}(1) \\
\text { Pensão alimentícia (1) }\end{array}$ \\
\hline Soure & $\begin{array}{l}\text { Pescadores e extrativistas de } \\
\text { caranguejo (12) } \\
\text { Autônomos (2) } \\
\text { Exerce a sua profissão? (11) }\end{array}$ & $\begin{array}{c}\text { Se locomove } 12 \mathrm{~km} \text { para a Vila do } \\
\text { Pesqueiro de bicicleta, motocicleta e a } \\
\text { pé (11) }\end{array}$ & $\begin{array}{l}\text { Menos de } 1 \text { SM (13) } \\
01 \text { a } 02 \text { SM (03) } \\
\text { Sem renda (2) }\end{array}$ & $\begin{array}{c}\text { Auxílio do PBF (14) } \\
\text { Seguro Defeso (13) } \\
\text { Aposentado (1); Pensão } \\
\text { Alimentícia (1); } \\
\text { BPC (1) }\end{array}$ \\
\hline
\end{tabular}

${ }^{*}$ Os entrevistados poderiam declarar receber mais de um benefício social; ${ }^{* *} \mathrm{SM}$ - Salário Mínimo; ${ }^{* * *} \mathrm{PBF}$ - Programa Bolsa Família; ${ }^{* * * * B P C ~-~ B e n e f i ́ c i o ~ d e ~ P r e s t a c ̧ a ̃ o ~ C o n t i n u a d a ; ~}{ }^{* * * \star *}$ DPVAT - Seguro de Danos Pessoais Causados por Veículos Automotores de Vias Terrestres.

Fonte: elaborado pelos/as autores/as com base na pesquisa de campo, 2019.

Esses dados são reveladores das condições de trabalho e renda no Brasil. Demonstram não somente as condições atuais da grave crise econômica, social e política do capitalismo contemporâneo, mas, as condições históricas de um país que tem na sua estrutura raízes escravocratas, patrimonialistas, com forte desigualdade de classe, racial e de gênero. São trabalhadores pardos e pretos, com pouco ou nenhum acesso à escola, dificuldade de acesso ao trabalho, baixíssima renda e, por esse motivo, dependentes dos programas de transferência de renda do governo federal. Há trechos das entrevistas que demonstram essa realidade: "Meu marido é caranguejeiro, nós vivemos disso, e recebo Bolsa Família, mas o caranguejo às vezes dá, às vezes não dá [...]. Mas agora está muito ruim, não está dando para tirar" (Moradora Z, Pesquisa de Campo, Soure, 2019).

Olha, aqui nós trabalhamos na roça, aqui a gente tem que plantar pra comer, nós não temos muitas opções, de trabalho, quero dizer [...]. Recebo 480,00 reais de Bolsa Família, então com isso fica difícil, não dá, já deixei de comprar coisas pros meus filhos e até coisas pra casa, armário, cama, essas coisas (Moradora A, Pesquisa de Campo, Abaetetuba, 2019). 


\title{
PROGRAMA NACIONAL DE HABITAÇÃO RURAL E CONDIÇÕES DE MORADIA EM PEQUENAS CIDADES NA AMAZÔNIA PARAENSE
}

Em relação à mensalidade/prestação da moradia, constatou-se que $60 \%$ dos moradores não conseguiram efetuar nenhum pagamento até a realização das entrevistas e que 72,5\% declararam ter dificuldades em pagar pela moradia. Contraditoriamente, mais da metade dos moradores $(57,5 \%)$ considerou bom ou ótimo o pagamento das parcelas da UH (Quadro 3). Vê-se que não se negam a pagar, mas, que suas condições objetivas não lhes permitem. As moradoras D e Z relatam sobre essa dificuldade de pagamento da mensalidade:

\begin{abstract}
Ainda não, ainda não comecei a pagar. Eu estou querendo pagar já em novembro porque agora, no momento, eu não estou podendo pagar ainda. Por que aqui a gente só trabalha com essas coisas, né? Pimenta, mandioca, só com essas coisas e muitas vezes não dá dinheiro, né, nessas coisas, as vezes vai da empresa, a gente vende para uma empresa e pra outra, né? (Moradora D, Pesquisa de Campo, Santa Izabel do Pará, 2019).
\end{abstract}

Ainda não paguei nenhuma, a gente recebe o seguro do pescador pra gente pagar a casa, só que meu RGP [Registro Geral de Pesca] está cancelado pelo MPA [Ministério da Agricultura, Pecuária e Abastecimento], então eu não estou recebendo, e ainda não paguei nenhuma parcela e eu também não tenho condição de pagar (Moradora Z, Pesquisa de Campo, Soure, 2019).

Em outro trecho de entrevista, a Moradora $\mathrm{D}$ reflete sobre as possibilidades de ter acesso à moradia pelo valor proposto no Programa:

\begin{abstract}
Quem é a pessoa, o ser humano que faz uma casa, hoje, desse tamanho com o valor que deram pra nós, né? $\mathrm{R} \$ 360,00$ por ano, eu tenho pra mim que na minha contagem dá $\mathrm{R} \$ 1.500,00$, né? Quem é que faz uma casa desse tamanho por $\mathrm{R} \$ 1.500,00$ reais? Ninguém faz (Moradora D, Pesquisa de Campo, Santa Izabel do Pará, 2019).
\end{abstract}

A opinião da Moradora D contribui para que se apreenda a aparente contradição entre a dificuldade de pagamento da mensalidade da UH do PNHR e a avaliação de que o valor da mensalidade é acessível. Revela-se com a pesquisa que, no cotidiano das famílias pobres da área rural, as pessoas, mesmo não dominando a lógica da propriedade privada da terra, do significado do valor de troca da habitação na ordem burguesa, conseguem perceber que o financiamento habitacional público de valor mais baixo é uma oportunidade de ter acesso a uma casa digna e diferente das condições precárias das casas que viviam antes. Entretanto, na vida concreta, a renda da família não permite que se efetive o pagamento.

Pode-se inferir que o morador, mesmo que tenha dificuldade de pagamento, avalia que a mensalidade não é tão cara, pois somente mediante um financiamento poderia ter acesso à casa. Como ressalta Diniz (2018, p. 274):

A moradia é, certamente, o bem de necessidade básica e essencial mais caro que uma família precisa, necessariamente, ter acesso para sobreviver. Ademais, seu custo está fortemente relacionado com o valor de terra, a partir de um mercado especulativo baseado na escassez. Em decorrência do alto custo, a única forma de acesso à moradia por uma 
família de baixa renda é por intermédio do aluguel ou do financiamento de longo prazo, alternativas que buscam relacionar a capacidade de pagamento ao custo da moradia.

No atendimento das necessidades básicas e de subsistência, verificou-se que os moradores se mostraram satisfeitos com a casa, embora indiquem que há problemas de infraestrutura e no aspecto construtivo das UH, as quais apresentam infiltrações, rachaduras e vazamentos, sendo necessário realizar adaptações. Nessa direção, o principal aspecto considerado positivo por $77,5 \%$ dos moradores foi a segurança que a casa possibilitou à família, por meio da estrutura física, retirando-os de situações de extrema precariedade habitacional (Quadro 3).

Quadro 3 - Aspectos sociais - Situação da moradia

\begin{tabular}{|c|c|c|c|c|c|}
\hline Município & $\begin{array}{l}\text { Pagamento da } \\
\text { mensalidade }\end{array}$ & $\begin{array}{l}\text { Atendimento das necessidades } \\
\text { da família }\end{array}$ & Ponto positivo & $\begin{array}{l}\text { Adequação do } \\
\text { número de } \\
\text { cômodos }\end{array}$ & $\begin{array}{l}\text { Adequação dos } \\
\text { quartos } x \text { número de } \\
\text { membros da família }\end{array}$ \\
\hline Abaetetuba & $\begin{array}{l}\text { Não conseguiram } \\
\text { pagar a mensalidade* } \\
\text { do PNHR (6) } \\
\text { Não haviam recebido o } \\
\text { boleto (2) } \\
\text { Relato de dificuldade } \\
\text { para pagamento (8) }\end{array}$ & $\begin{array}{l}\text { A casa atende às necessidades } \\
\text { da família, embora relatem } \\
\text { problemas no material } \\
\text { construtivo ( } 7 \text { ) } \\
\text { Relato de falta de água } \\
\text { encanada (1) }\end{array}$ & $\begin{array}{l}\text { Segurança da } \\
\text { moradia (8) }\end{array}$ & $\begin{array}{l}\text { Número de cômodos } \\
\text { adequados à família } \\
\text { (7) }\end{array}$ & $\begin{array}{l}\text { A maioria dos membros } \\
\text { da família dorme nos } \\
\text { quartos (7) } \\
01 \text { membro da família } \\
\text { dorme fora do quarto (1) }\end{array}$ \\
\hline $\begin{array}{l}\text { Santa Izabel } \\
\text { do Pará }\end{array}$ & $\begin{array}{l}\text { Não receberam o } \\
\text { boleto e por isso não } \\
\text { pagaram (14) } \\
\text { Relato de dificuldade } \\
\text { para pagamento futuro } \\
\text { (6) }\end{array}$ & $\begin{array}{l}\text { A casa atende às necessidades } \\
\text { da família (10) } \\
\text { Relatado de problemas (calçada } \\
\text { alta/locomoção de idosos, falta } \\
\text { de armador de rede etc.) (04) }\end{array}$ & $\begin{array}{l}\text { Segurança da } \\
\text { moradia (13) }\end{array}$ & $\begin{array}{l}\text { Número de cômodos } \\
\text { adequados à família } \\
\text { (13) }\end{array}$ & $\begin{array}{l}\text { Todos os membros da } \\
\text { família dormem nos } \\
\text { quartos }\end{array}$ \\
\hline Soure & $\begin{array}{l}\text { Pagaram pelo menos } \\
\text { uma mensalidade do } \\
\text { PNHR (14) } \\
\text { Relato de dificuldade } \\
\text { para pagamento (15) }\end{array}$ & $\begin{array}{l}\text { A casa atende às necessidades } \\
\text { da família (15) } \\
\text { Não atende (3) }\end{array}$ & $\begin{array}{l}\text { Custo acessível } \\
\text { da moradia (11) } \\
\text { Segurança e } \\
\text { saneamento (10) }\end{array}$ & $\begin{array}{l}\text { Número de cômodos } \\
\text { adequados à família } \\
\text { (10) } \\
\text { Número de cômodos } \\
\text { não adequados à } \\
\text { família (8) } \\
\text { f }\end{array}$ & $\begin{array}{l}\text { A maioria dos membros } \\
\text { da família dorme } \\
\text { somente nos quartos } \\
\text { (11) } \\
\text { Dormem fora do quarto } \\
\text { (07) }\end{array}$ \\
\hline
\end{tabular}

*Valor da mensalidade: 4 parcelas anuais no valor de $\mathrm{R} \$ 360,00$ (trezentos e sessenta reais).

Fonte: elaborado pelos/as autores/as com base na pesquisa de campo, 2019.

A fala de duas entrevistadas demonstra a satisfação e, ao mesmo tempo, os problemas com material construtivo das residências recebidas:

Olha mudou muita coisa na nossa vida, porque meu sonho era ter uma casa lajotada, e toda mobiliada com as minhas coisas, só que eu ainda não pude conseguir isso. Mas estou feliz com a casa [...]. Eu já relatei sobre a infiltração nas paredes, é em toda a casa, tudo. Mas tirando isso eu gostei do trabalho, que trouxe segurança, uma casa que nem todo mundo consegue, uma casa dessa. E com o dinheiro que é mil e poucos reais, a gente não consegue comprar nem o material de ferragem que colocaram nessa casa (Moradora $A$, Pesquisa de Campo, Abaetetuba, 2019).

Olha, satisfeita eu não estou não. Porque ela já tá com algumas falhas que tivemos que ajeitar tudinho de novo, no banheiro o negócio da água não vai pra lá e tá entupido. $\mathrm{A}$ cobertura da área de trás teve que ser reforçada que estava caindo (Moradora Z, Pesquisa de Campo, Soure, 2019).

Identificou-se que as famílias, em sua maioria, têm composição familiar de 02 a 04 pessoas. No entanto, em Abaetetuba, houve 01 situação de coabitação familiar. Em Soure, a questão é mais expressiva, havendo 04 situações de famílias com mais de 10 pessoas, com pelo menos duas ou 


\section{PROGRAMA NACIONAL DE HABITAÇÃO RURAL E CONDIÇÕES DE MORADIA EM PEQUENAS CIDADES NA AMAZÔNIA PARAENSE}

três famílias conviventes na mesma residência, em circunstâncias de pessoas dormindo na área externa da casa (Quadro 3).

Entre essas residências, foi identificado que um casal de idosos dorme de forma improvisada em uma área externa à UH utilizada para cultivo de hortaliças. Os moradores relataram que, nas noites chuvosas, esperam a chuva passar para que possam atar suas redes naquele espaço e, assim, dormirem. Essas estratégias de sobrevivência chamam atenção para as condições extremas de inadequação habitacional em virtude do adensamento excessivo na UH, o que ocorre mesmo após a implementação do programa.

Vale registrar que os moradores beneficiados pelo PNHR passaram a residir em casas de quatro cômodos construídas com o mesmo padrão de edificação e com metragem de $42 \mathrm{~m}^{2}$. As unidades são compostas por uma sala conjugada com a cozinha, dois quartos e um banheiro, além de uma pequena área de serviço coberta na parte de trás (figuras 1, 2 e 3).

Figura 1 - Condições de moradia no município de Abaetetuba
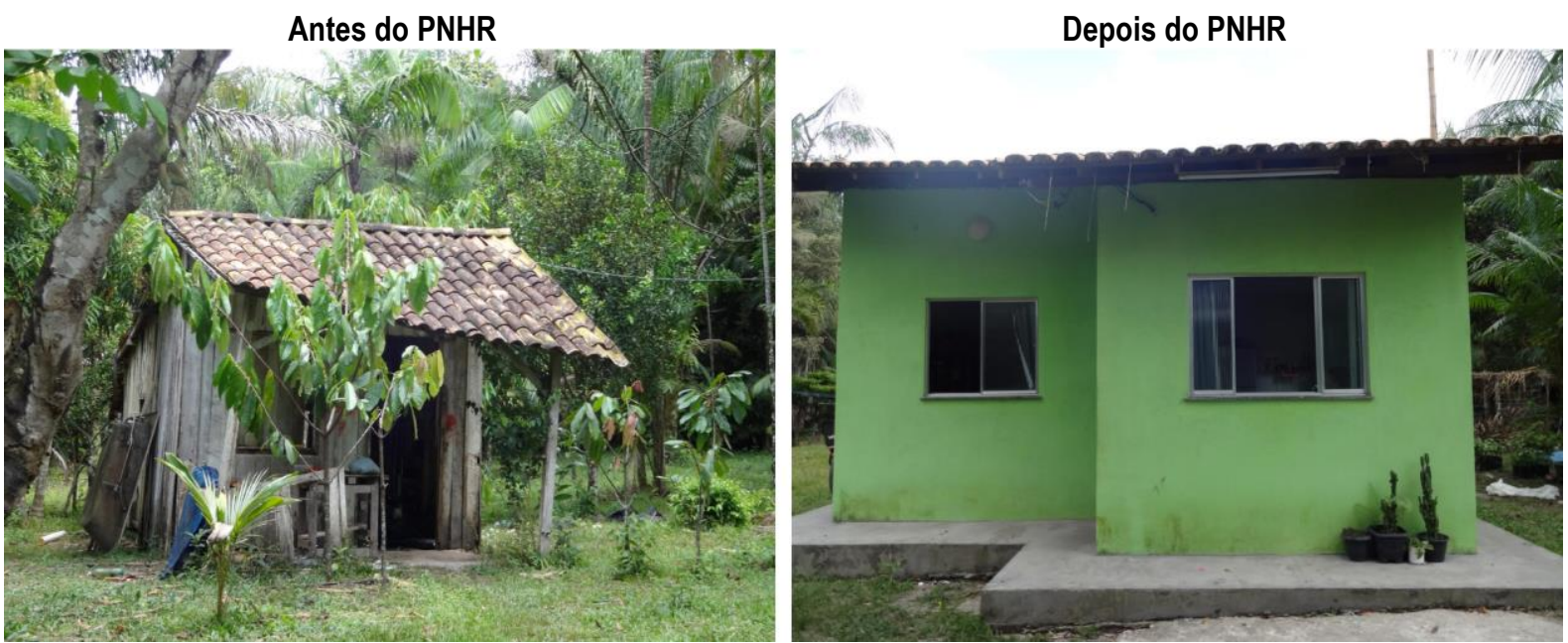

Fonte: Acervo GEP-CIHAB, 2019.

Figura 2 - Condições de moradia no município de Santa Izabel/Agrovila Ferreira Pena
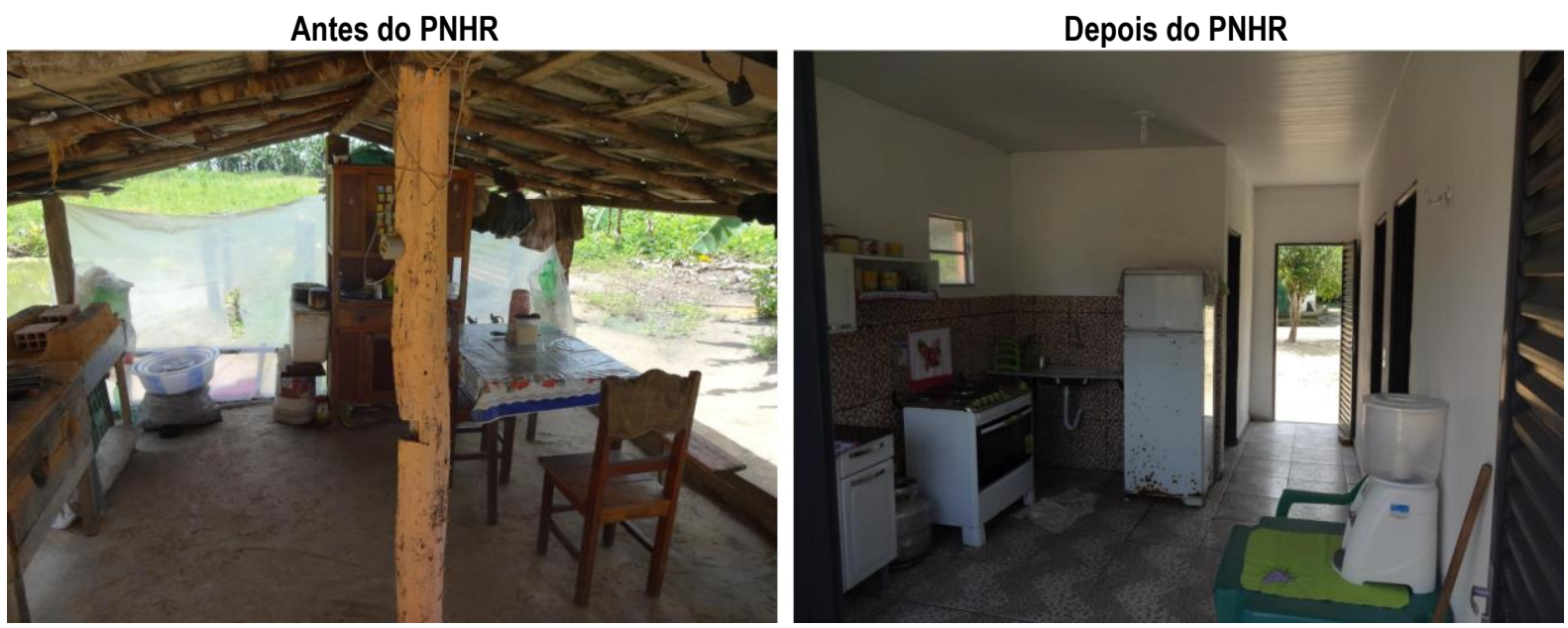

Fonte: Acervo GEP-CIHAB, 2019. 
Figura 3 - Condições de moradia no município de Soure/Tucumanduba
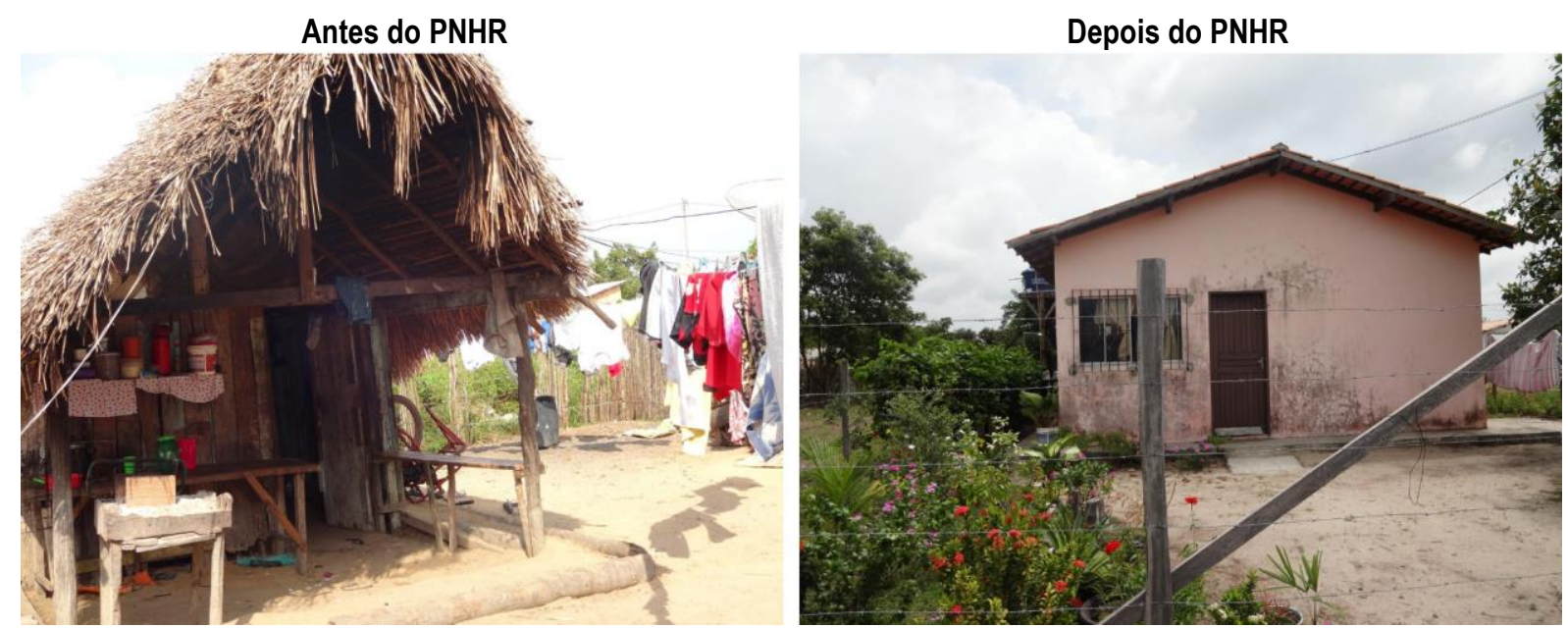

Fonte: Acervo GEP-CIHAB, 2019.

As figuras 1, 2 e 3 contribuem para que se apreendam algumas determinações do modo de morar nas áreas rurais estudadas e das aparentes contradições relativas às novas condições de moradia. Observa-se que há sentimento de satisfação dos moradores com a nova casa, embora reconheçam que as UH foram entregues com problemas de infraestrutura. Os mesmos moradores também dizem estar satisfeitos com o valor da mensalidade das $\mathrm{UH}$, mesmo que não consigam pagar.

As condições de moradia nas antigas residências (como aparece à esquerda nas figuras) explicam o sentimento de insegurança nessas casas com precária infraestrutura, sem portas e janelas, deixando os moradores intranquilos, especialmente, para dormir. Dessa forma, as casas com melhor infraestrutura contribuem para que a mudança em relação às condições de segurança seja apontada como fundamental na vida dos moradores. As entrevistadas (uma moradora e uma Assistente Social do município) relatam:

Foi, ficou tudo em segurança porque eu tinha muito medo de dormir lá [na antiga casa], porque era só uma tábua e um pau escorado [...] e aqui não, eu durmo tranquila, tranquila, tem chave nas portas, né [...] (Moradora D, Pesquisa de Campo, Santa Izabel do Pará, 2019).

Ao que se observa os impactos mais visualizados referem-se a estruturas físicas das unidades habitacionais, uma vez que as famílias beneficiadas conseguem mais dignidade de moradia. Como por exemplo a inserção de banheiro/sanitário dentro dos imóveis. Bem como proporciona que famílias em situação de coabitação involuntária consigam suas próprias unidades habitacionais (Assistente Social P, Pesquisa de Campo, Santa Izabel do Pará, 2019).

A visualização dessas imagens permite a compreensão - a partir de questões objetivas e subjetivas dos moradores - da satisfação que sentem ao receber uma casa nova com um mínimo de infraestrutura, deixando para trás a antiga casa com precária qualidade construtiva e, em muitos casos, sem banheiro ou com banheiro externo. Sobre o assunto, duas moradoras relatam: "O maior benefício 
que essa casa trouxe foi a parte do banheiro, porque a gente não tinha e fazia sanitário fora da casa" (Moradora Z, Pesquisa de Campo, Soure, 2019).

\begin{abstract}
Eu morava aqui nesse quartinho [...]. Eu tinha vontade de ter uma casinha, né, boa, porque essa casa minha aí, toda vez que chovia, molhava, molhava, molhava, não tinha estrutura, nada. Era só mesmo as paredes, mas eu nunca tive condições de botar uma porta boa, né, uma janela. Botava telha de "brazilite" pra dormir, aí as telhas tão furadas, aí quando eu dormia à noite, e chovia forte, molhava tudo dentro de casa [...] (Moradora $\mathrm{D}$, Pesquisa de Campo, Santa Izabel do Pará, 2019).
\end{abstract}

A pesquisa procurou identificar qual a situação dos serviços públicos ofertados, o acesso e a avaliação dos moradores a esses serviços. Em relação ao serviço de abastecimento de água, em Santa Izabel e em Soure, houve avaliação positiva pelos moradores, com acesso à água encanada, caixa d'água coletiva; poço tipo boca aberta e poço artesiano com bomba elétrica. Por sua vez, em Abaetetuba, houve avaliação negativa pela grande maioria dos moradores entrevistados porque as $\mathrm{UH}$ não possuem água encanada por empresa pública, motivo pelo qual todos têm poço (63\% poço artesiano com bomba e $37 \%$ é poço normal, do tipo boca aberta).

Quanto ao abastecimento de energia elétrica, a maioria possui acesso fornecido pela Rede Celpa/Equatorial e paga taxa entre $\mathrm{R} \$ 71,00$ e $\mathrm{R} \$ 100,00$. Um número expressivo de moradores faz ligação clandestina ("gato") direta dos postes e/ou da casa de parentes, por não terem condições para pagar a energia.

Sobre o serviço de coleta de lixo, a maioria dos moradores de Santa Izabel e Soure 0 avaliou de forma positiva, embora se registre um número significativo daqueles que acondicionam o lixo em latas ou queimam no quintal. Em Abaetetuba, houve avaliação negativa desse serviço pela maioria dos entrevistados, pois não ocorre de forma regular, com dias certos para coleta, o que torna o serviço incipiente e precário.

Os serviços de saúde, educação e segurança foram avaliados positivamente pela maior parte dos entrevistados em todos os municípios. Sobre o serviço de saúde, em Abaetetuba, metade dos moradores avaliou como bom e regular e a outra metade, como ruim e péssimo, uma vez que, o posto de saúde, bem como a Unidade de Pronto Atendimento (UPA), ficam distantes das localidades.

A pesquisa não identificou a oferta de equipamentos ou espaços públicos destinados ao lazer, com exceção de Santa Izabel, onde existe uma pequena praça, motivo pelo qual a maioria dos moradores avaliou a oferta desse serviço como ruim ou péssimo. Por sua vez, os moradores informaram que se divertem no banho dos igarapés, indo à igreja, jogando baralho, jogando nos campos de futebol e indo à praia.

O serviço de transporte e 0 de pavimentação e manutenção de infraestrutura foram avaliados negativamente pela maioria dos moradores pesquisados nos três municípios. 
Em relação ao serviço sanitário e de esgoto, houve diferenciações no resultado da pesquisa. Em Abaetetuba, metade dos moradores avaliou como bom e a outra metade, como ruim. Em Santa Izabel, a maioria avaliou positivamente, enquanto em Soure, a maioria avaliou negativamente. Em todos os municípios investigados, o acesso à feira/mercado foi avaliado de forma negativa pelos participantes.

Os dados demostram que os locais onde foram construídas as UH apresentam problemas de água, saneamento básico, transporte, pavimentação e ausência de espaços de lazer. Em Abaetetuba, os moradores não possuem água encanada, o que é um problema gravíssimo, considerando que precisam buscar outras soluções (como a construção de poços) para ter acesso à água.

A taxa de energia elétrica é um dado da realidade que chama bastante atenção, pois não é proporcional à faixa de renda dos moradores. Os valores pagos pelo consumo de energia elétrica variam entre $R \$ 71,00$ e $R \$ 100,00$, o que pode ser considerado exorbitante para as condições de reprodução social das famílias, as quais deveriam ter acesso à tarifa social.

A avaliação positiva dos serviços de esgotamento sanitário e segurança provavelmente se explica pelas precárias condições da moradia anterior. Entre outras mudanças, a nova casa possui fossa séptica com banheiro interno, realidade diferente do que se vivenciava antes. A satisfação com a nova residência é ilustrada na opinião da Moradora N: "É, gostei né? Porque a minha casinha já tá bem deteriorada [...]. Não é grande, mas fica essa aí. A menina está aí. Quando vierem as pessoas podem dormir aí comigo" (Moradora N, Pesquisa de Campo, Santa Izabel do Pará, 2019).

A pesquisa buscou identificar, ainda, os principais problemas, as melhorias proporcionadas pelo Programa e do que o morador sente falta em sua moradia. Como principais problemas apontados pelos moradores após a implementação do PNHR, se destacam a falta de recursos para melhorar ou modificar o espaço da residência (70\%), seguido do aumento no custo de vida $(52,5 \%)$ e aumento da taxa de energia elétrica (47,5\%). As principais melhorias proporcionadas foram 0 acesso à escola e ao posto de saúde $(67,5 \%)$, a permanência da relação com familiares e com a vizinhança $(57,5 \%)$, além do aumento na segurança (35\%).

Sobre o que sentem falta em suas casas, as respostas nos três municípios foram unânimes: os moradores sentem falta de uma cozinha grande $(87,5 \%)$ e de uma área de pátio $(77,5 \%)$. Perguntados sobre como gostariam que fosse a sua casa, os entrevistados responderam que gostariam de uma cozinha mais ampla (35\%), de uma casa com área de pátio $(32,5 \%)$ e de uma residência em que a sala fosse separada da cozinha (30\%). Percebe-se que para os interlocutores da pesquisa a área da cozinha e do pátio são espaços importantes para a convivência familiar. Os 
moradores também dizem sentir falta de uma área coberta próximo à cozinha, de mais janelas e de cômodos mais amplos, o que demonstra dificuldades relativas à pouca ventilação e iluminação no padrão construtivo das casas (Quadro 4).

Quadro 4 - Como o morador gostaria que fosse sua moradia

\begin{tabular}{|c|l|}
\hline Município & \multicolumn{1}{c|}{ Descrição dos moradores } \\
\hline Abaetetuba & $\begin{array}{l}\text { Sala e cozinha separadas (4); Ter mais um quarto (1); Espaço fora da casa ("puxada”) (1); Retirar o } \\
\text { forro para melhorar a temperatura (1); Construir dois andares e ter banheiro nos quartos (1) }\end{array}$ \\
\hline $\begin{array}{c}\text { Santa Izabel do } \\
\text { Pará }\end{array}$ & $\begin{array}{l}\text { Ter uma área de pátio (5); Sala e cozinha separadas (4); Aumentar a cozinha (4); Espaço fora da casa } \\
\text { ("puxada") (3); Varanda (2); Ter mais um quarto (1) }\end{array}$ \\
\hline Soure & $\begin{array}{l}\text { Ter uma área de pátio (7); Aumentar a cozinha (6); Ter mais um quarto (5); Sala e cozinha separadas } \\
\text { (4); Ter mais janelas (2); Gostaria de ter um poço (1) }\end{array}$ \\
\hline
\end{tabular}

Fonte: elaborado pelos/as autores/as com base na pesquisa de campo, 2019.

A descrição apresentada no quadro é reforçada na fala das moradoras:

Assim, o que eu sinto falta, por exemplo, é sala e cozinha ao mesmo tempo, né. Aí eu tinha vontade de uma cozinha maior, separada né, mas não foi possível [...], mas eu estou muito satisfeita [...]. Eu não ia ter condições de fazer nem assim, então eu estou muito satisfeita, muito mesmo [...]. Isso é vontade, condição eu não tenho (Moradora D, Pesquisa de Campo, Santa Izabel do Pará, 2019).

Atende as necessidades básicas não. Eu precisei aumentar a parte de trás, para ampliar a cozinha, porque quando era aqui na frente eu não conseguia cozinhar e agora não, apesar de ser chão batido pude colocar a mesa, o fogão de carvão e o jirau (Moradora G, Pesquisa de Campo, Soure, 2019).

No que diz respeito à disposição dos cômodos, bem como à utilização dos mesmos pelos moradores, Santos (2014) destaca que é importante compreender o significado e as expectativas de moradia dos beneficiários do PNHR, e como seus desejos e necessidades estão sendo contemplados pelo referido Programa, posto que:

O PNHR introduz no meio rural uma nova perspectiva de "casa" com peculiaridades de um ambiente com configurações urbanas, ignorando valores e costumes do meio rural. Contudo, por mais que novas estruturas habitacionais sejam notadas no ambiente doméstico familiar rural, como, por exemplo, a disposição dos cômodos, valorização, necessidade e desejo atribuído aos mesmos e aos mobiliários, eletrodomésticos e eletroeletrônicos, houve uma restrição, de parte dos beneficiários com relação ao projeto habitacional imposto - visto que nenhuma pesquisa de campo foi realizada previamente para verificar o modelo de casa a ser elaborado, e que o projeto de construção necessita ser seguido de forma rigorosa (SANTOS, 2014, p. 103).

Nessa direção, os resultados do estudo realizado por Santos (2014) sobre o PNHR em duas cidades mineiras apontam que o programa habitacional voltado para a população residente no campo estava dentro de uma lógica de uniformização que não contempla as especificidades presentes nas representações desses grupos. Isto é mostrado por características tais como a sala conjugada com a cozinha, a eliminação do espaço para o fogão a lenha, o número de quartos e o tamanho reduzido da 
varanda em um dos municípios, assim como pelo tamanho reduzido da cozinha, que impede a reunião da família nesse ambiente.

Santana, Holanda e Moura (2012) demonstram que a região Norte possui municípios com alto nível de pobreza; precariedade de infraestrutura logística (acesso rodoviário e fluvial); e forte carência de infraestrutura, com destaque para o saneamento básico. Mas, além disso, destacam que essa região possui particularidades no modo de viver dos habitantes das "comunidades ribeirinhas, quilombolas, indígenas que demandam tipologias diferenciadas na construção da moradia" (p. 19). Os dados de pesquisa apresentados nesta seção confirmam que as políticas públicas para o meio rural carecem de maior conhecimento sobre essas realidades.

\section{CONSIDERAÇÕES FINAIS}

A pesquisa identificou as contradições inerentes às políticas estatais no contexto do modo de produção capitalista. O PNHR, ao mesmo tempo em que pode ser considerado importante no contexto da política habitacional brasileira por significar a possibilidade de os moradores das áreas rurais terem acesso à moradia no Brasil, de modo a alterar as condições de precariedade habitacional tão graves, como visto na pesquisa, apresenta limites, visto que os moradores com baixa renda têm dificuldades de arcar com os custos da nova moradia.

Assim, ao analisar o direito à moradia no âmbito rural em cidades paraenses e as respostas apresentadas pelo Programa, os resultados apontam que a realidade socioeconômica dos moradores não acompanha os custos com as prestações da casa, com as taxas dos serviços (principalmente, com o preço da energia elétrica) para a manutenção da casa e com as necessidades básicas das famílias, pois as casas apresentam uma padronização que não atende ao número de pessoas na família, sendo necessário criar estratégias de sobrevivência, como dormir fora do espaço da casa.

O estudo corrobora com os dados de outras pesquisas que demonstram vários problemas na concepção e implementação do Programa Minha Casa Minha Vida, com destaque para a ausência da incorporação da diversidade regional no Brasil (BALBIM; KRAUSE; LIMA NETO, 2015), o que se confirma para o caso das políticas habitacionais na região Amazônica (RIBEIRO, 2012; SANTANA; HOLANDA; MOURA, 2012).

Discutir o significado do rural em pequenas cidades paraenses no que se refere à questão habitacional remete a hábitos de moradia, costumes e práticas tradicionais das populações que ali moram, as quais incorporam aspectos da vida urbana sem perder essas práticas no seu cotidiano, 
mantendo estreita relação com a natureza para manter seu sustento bem como para momentos de lazer; preservando o hábito de lavar louças no jirau, cozinhar os alimentos em fogão a lenha ou carvão; de reunir a família no espaço da cozinha ou realizar as refeições na barraca ao ar livre.

Evidencia-se, assim, que o PNHR, ao pensar a construção, estrutura e estética das UH, não considera essas particularidades, desvalorizando esses aspectos culturais da forma amazônica de habitar e ocupar os espaços rurais, que se traduzem por espaços construídos demasiadamente pequenos.

Dessa forma, os resultados identificados com a pesquisa revelam que a implementação do PNHR contribuiu para a diminuição da situação de extrema precariedade habitacional das famílias, mas, não alterou em sua totalidade as condições de vida dos moradores, uma vez que, o acesso à casa não se traduziu efetivamente em condições de habitabilidade, salubridade, de acesso aos serviços e equipamentos públicos e qualidade das moradias, como está previsto nos objetivos do Programa. Pode-se inferir, portanto, que as famílias não foram atendidas na maioria dos aspectos socioeconômicos apresentados como indicadores desta pesquisa.

Além disso, os resultados apresentados ratificam que a política habitacional, por meio do PNHR, pouco considera e se aproxima da realidade da região, posto que apenas o aspecto da segurança foi apontado pelos moradores como fator positivo com a nova casa; os demais elementos considerados essenciais para a efetivação do direito à moradia, como infraestrutura básica, acesso aos serviços básicos, custo da moradia acessível, habitabilidade, localização e qualidade das moradias não se apresentaram como pontos positivos determinantes para os sujeitos da pesquisa.

O estudo demonstra a importância de se avançar nas pesquisas sobre o modo de vida rural, considerando o papel da ciência em investigar a realidade, apresentar sínteses e propor indicadores socioeconômicos que possam subsidiar a produção habitacional rural, isto é, propor ferramentas para o planejamento e execução das políticas e programas direcionados para a realidade da população rural, respeitando as particularidades regionais.

\section{REFERÊNCIAS}

BALBIM, R.; KRAUSE, C.; LIMA NETO, V. C. Para além do Minha Casa Minha Vida: uma política de habitação de interesse social? Texto Para Discussão, Rio de Janeiro: Ipea, n. 2116, ago. 2015. Disponível em: http://repositorio.ipea.gov.br/bitstream/11058/5282/1/td_2116.pdf. Acesso em: 13 ago. 2020.

BRASIL. Ministério das Cidades. Manual do Programa Nacional de Habitação Rural. Brasília, DF, 2012. 
CARDOSO, A. C. D.; LIMA, J. J. F. Tipologias e padrões de ocupação na Amazônia Oriental: para que e para quem? In: CARDOSO, A. C. D. (org.). 0 rural e o urbano na Amazônia: diferentes olhares em perspectivas. Belém, PA: Edufpa, 2006. p. 55-96.

CASTRO, E. Dinâmicas sociais e territoriais das pequenas e médias cidades na Amazônia. In: CARDOSO, A. C. D. (org.). 0 rural e o urbano na Amazônia: diferentes olhares em perspectivas. Belém, PA: Edufpa, 2006. p. 9-22.

CASTRO, E. Integração Sul-Americano do IIRSA - Visão do Estado e dos atores da Pan-Amazônia. In: ALMEIDA, A. W. B.; CARVALHO, G. 0 plano IIRSA: na visão da sociedade civil pan-amazônica. Belém, PA: Actionaid, 2009. p. 107-141.

DINIZ, T. M. R. G. Políticas Urbanas Habitacionais e o Projeto Ético-Político: em defesa do direito à cidade e da moradia digna. In: SANTANA, J. V. (org.). Habitação e Serviço Social: dimensões teóricas, históricas e metodológicas. Campinas: Papel Social, 2018. p. 269-284.

ENGELS, F. Sobre a questão da moradia. Tradução: Nélio Schneider. São Paulo: Boitempo, 2015.

HARVEY, D. A justiça social e a cidade. São Paulo: Hucitec, 1980.

HOLANDA, A. C. G.; SANTANA, J. V. Avanços e limites da nova Política Nacional de Habitação: reflexões sobre a descentralização a partir do caso do estado do Pará. In: SANTANA, J. V.; HOLANDA, A. C. G.; MOURA, A. S. F. (orgs.). A questão da habitação em municípios periurbanos na Amazônia. 1. ed. Belém, PA: Edufpa, 2012. p. 183-198.

HOLANDA, A. C. G. A nova Política de Habitação de Interesse Social no Pará (2007-2010): avanços e limites. 2011. Dissertação (Mestrado em Planejamento do Desenvolvimento) - Núcleo de Altos Estudos Amazônicos, Universidade Federal do Pará, Belém, PA, 2011.

INSTITUTO BRASILEIRO DE GEOGRAFIA E ESTATÍSTICA. [Brasil/Pará/Panorama]. 2020b. Disponível em: https://cidades.ibge.gov.br/brasil/pa/panorama. Acesso em: 6 jun. 2020.

INSTITUTO BRASILEIRO DE GEOGRAFIA E ESTATÍSTICA. Cidades e Estados. 2020a. Disponível em: https://www.ibge.gov.br/cidades-e-estados/pa/. Acesso em: 6 jun. 2020.

LIMA, A. T. O. et al. Programas habitacionais federais no Pará: desigualdades e contradições na política de habitação. Cadernos CEPEC, v. 6, n. 7-12, p. 4-28, 2017. Disponível em: https://periodicos.ufpa.br/index.php/cepec/article/view/7040. Acesso em: 13 ago. 2020.

MARQUES, G. Amazônia: uma moderna colônia energético-mineral? Universidade e Sociedade, Brasilia, DF: ANDES-SN, v. 21, n. 49, jan. 2012.

MARX, K. Introdução à crítica da Economia Política. In: MARX, K. Manuscritos econômicofilosóficos e outros textos escolhidos. São Paulo: Abril Cultural, 1974. (Os Pensadores). p. 102-125.

OLIVEIRA, J. A. As pequenas cidades da Amazônia: espaços perdidos e reencontrados. In: DUMIANI, A.; CARLOS, A.; SEABRA, O. (org.). 0 espaço no fim do século: a nova raridade. São Paulo: Contexto, 1999. p. 199-211. 
PARÁ. Companhia de Habitação do Estado do Pará. Síntese e atualização do Plano Estadual de Habitação de Interesse Social (2013/2014). Belém, PA, 2014.

PERDIGÃO, A. K. A. V.; SANTANA, J. V. Produção habitacional e participação popular no reassentamento de famílias em Belém (PA). In: SANTANA, J. V. (org.). Habitação e Serviço Social: dimensões teóricas, históricas e metodológicas. Campinas: Papel Social, 2018. p. 215-232.

PETERSEN, A. M. A participação do movimento de pequenos agricultores na execução do Programa Nacional de Habitação Rural no Espírito Santo. 2015. Dissertação (Mestrado) Programa de Pós-Graduação em Política Social, Universidade Federal do Espírito Santo, Vitória, 2015. Disponível em: <http://repositorio.ufes.br/handle/10/10405>. Acesso em: 13 ago. 2020.

RIBEIRO, R. A Política Habitacional recente e sua expressão em municípios da Amazônia Oriental: os exemplos de São Sebastião da Boa Vista e São João do Araguaia - PA. In: SANTANA, J. V.; HOLANDA, A. C. G.; MOURA, A. S. F. (orgs.). A questão da habitação em municípios periurbanos na Amazônia. 1. ed. Belém, PA: Edufpa, 2012. p. 215-246.

ROVER, O. J.; MUNARINI, P. R. A política de habitação rural e o desenvolvimento da agricultura familiar. Revista Katálysis, Florianópolis, v. 13, n. 2, p. 260-269, jul./dez. 2010. DOI: https://doi.org/10.1590/S1414-49802010000200013.

SANTANA, J. V.; HOLANDA, A. C. G.; MOURA, A. S. F. (orgs.). A questão da habitação em municípios periurbanos na Amazônia. 1. ed. Belém, PA: Edufpa, 2012.

SANTANA, J. V. Habitação. Brasil em Números, v. 26, p. 93-108, 2018.

SANTOS, S. N. Realidade, significado e expectativas do Programa Nacional de Habitação Rural: o caso de Guiricema e São Miguel do Anta - MG. 2014. Dissertação (Mestrado em Economia Doméstica) - Universidade Federal de Viçosa, Viçosa, 2014. Disponível em: https://www.locus.ufv.br/handle/123456789/3397. Acesso em: 13 ago. 2020.

TEIXEIRA, J. B. Meio ambiente, Amazônia e Serviço Social. Em Pauta, Rio de Janeiro: UERJ, n. 21, p. 140-152, 2008. Disponível em: https://www.epublicacoes.uerj.br/index.php/revistaempauta/article/view/94. Acesso em: 13 ago. 2020.

\section{Notas}

1 -Pesquisa desenvolvida no âmbito do Grupo de Estudos e Pesquisa Cidade, Habitação e Espaço Humano (GEP-CIHAB), vinculado ao Programa de Pós-Graduação em Serviço Social (PPGSS) da Universidade Federal do Pará (UFPA).

2 A pesquisa documental priorizou o levantamento das fichas cadastrais dos beneficiários do PNHR junto às Entidades Organizadoras em cada município (Abaetetuba, Santa Izabel do Pará e Soure), para verificar os dados dos sujeitos da pesquisa.

\footnotetext{
${ }^{3}$ A pesquisa de campo foi realizada entre os meses de fevereiro e julho de 2019 , sendo precedida da entrega de carta convite aos moradores e contato com as Prefeituras dos municípios. As entrevistas foram autorizadas com a assinatura do Termo de Consentimento Livre e Esclarecido (TCLE), preservando-se a identidade dos entrevistados. A pesquisa foi submetida à Plataforma Brasil e ao Comitê de Ética em Pesquisa da UFPA, sendo aprovada sob $n^{0}$ CAAE 14177219.0.0000.0018.
} 
4 Os critérios de inclusão desses municípios foram: a) serem pequenos municípios; b) terem recebido contratações para produção habitacional rural no período de 2008 a 2015; c) terem obras concluídas e entregues aos beneficiários; d) possuírem equipe técnica multiprofissional atuando junto com as Entidades Organizadoras do Programa, nas fases de execução do PNHR; e) pertencerem à Região de Integração Tocantins, Guamá e Marajó, as quais apresentam significativo déficit rural no Pará e possuem população bastante significativa na área rural dos municípios.

5 Segundo Rover e Munarini (2010, p. 261), o Governo Federal iniciou o PNHR em 2003 com o objetivo de reduzir o histórico déficit habitacional dos territórios rurais, oferecendo acesso facilitado à política social de habitação rural por parte dos agricultores familiares em condições socioeconômicas mais vulneráveis. 